\title{
Regulation of circulating endocannabinoids associated with cancer and metastases in mice and humans
}

\author{
Sebastian Sailler ${ }^{1}$, Katja Schmitz ${ }^{1}$, Elke Jäger ${ }^{2}$, Nerea Ferreiros ${ }^{1}$, Sabine Wicker ${ }^{3}$, \\ Katja Zschiebsch ${ }^{1}$, Geethanjali Pickert ${ }^{1}$, Gerd Geisslinger ${ }^{1}$, Carmen Walter ${ }^{1}$, \\ Irmgard Tegeder ${ }^{1, *}$, and Jörn Lötsch ${ }^{1, *}$ \\ 1 pharmazentrum frankfurt/ZAFES, Institute of Clinical Pharmacology, Goethe-University Hospital, Frankfurt am Main, \\ Germany \\ ${ }^{2}$ Department of Hematology and Oncology, Krankenhaus Nordwest, Frankfurt am Main, Germany \\ ${ }^{3}$ Occupational Health Service, University Hospital Frankfurt, Frankfurt am Main, Germany. \\ * These authors contributed equally to this work
}

Correspondence to: Jörn Lötsch, email: j.loetsch@em.uni-frankfurt.de,

Keywords: Cannabinoids, Human, Mice, Metastasis

Received: January 30, $2014 \quad$ Accepted: April 30, 2014

Published: April 30, 2014

This is an open-access article distributed under the terms of the Creative Commons Attribution License, which permits unrestricted use, distribution, and reproduction in any medium, provided the original author and source are credited.

ABSTRACT:

Background and aims: Endocannabinoids may modify cancer development, progression and associated pain. We determined whether cancer-evoked dysregulations in this system become manifest in altered tissue and plasma endocannabinoids.

Methods: Endocannabinoid changes due to cancer were explored in a local and metastatic syngeneic mouse melanoma model. Endocannabinoid stratification in human cancer was cross-sectionally assessed in the plasma of 304 patients (147 men, 157 women, aged 32 - 87 years) suffering from several types of cancer at Roman Numeral Staging between I and IVc, mostly IV $(n=220)$, and compared with endocannabinoids of healthy controls.

Results: In mice with local tumor growth, ethanolamide endocannabinoids, i.e., anandamide (AEA), palmitoylethanolamide (PEA) and oleoylethanolamide (OEA) were downregulated, whereas 2-arachidonoylglycerol (2-AG) was increased. Upon spreading of the cancer cells particularly 2-AG steadily increased in parallel to disease progression while OEA modulated cell migration. Results translated into humans, in whom cancer was associated with a decreased AEA, increased 2-AG and increased OEA correlating with the number of metastases.

Conclusions: The endocannabinoid system was subject to cancer-associated regulations to an extent that led to measurable changes in circulating endocannabinoid levels, emphasizing the importance of the endocannabinoid system in the pathophysiology of cancer.

\section{INTRODUCTION}

Endocannabinoids (Figure 1) are involved in several ways in cancer pathophysiology including inflammation, tumor progression and pain. The lipid mediators arachidonoyl ethanolamide (anandamide, AEA) and 2-arachidonoyl glycerol (2-AG) exert their effects via agonist binding at cannabinoid $\mathrm{CB}_{1}$ and $\mathrm{CB}_{2}$ receptors [1] whereas structural relatives, e.g., palmitoylethanolamide
(PEA) and oleoylethanolamide (OEA), exert their effects via orphan G-protein coupled receptors (e.g. GPR18, 55, 92 and 119 [2]) or nuclear receptors PPAR $\gamma$ and $\alpha$ [3].

Endocannabinoids inhibit tumor proliferation via direct effects on tumor cells [4] in breast, brain, skin, thyroid, prostate and colorectal cancers [5, 6] and via the suppression of angiogenesis and tumor invasion [7]. They contribute to failures of the immune system to attack tumors by favoring $\mathrm{CB}_{2}$ mediated polarization 
of tumor-associated macrophages and dendritic cells toward tumor tolerance [8, 9]. Particularly anandamide causes a silencing of macrophage-like cells and release of inhibitory cytokines $[10,11]$ whereas $2-A G$ acts oppositely [12]. Endocannabinoid release from tumors modifies the tumor environment, immune cell infiltration and tumor attack [13] and may favor tumor growth whereas high endocannabinoid concentrations may inhibit tumor growth [14-18].

Thus, several lines of evidence support that tumor development and progression may be associated with disturbances of the endocannabinoid balance. Endocannabinoids originating from tumors apparently contribute to the plasma endocannabinoid pool [19], however, without a consistent pattern [5, 6]. The present study addressed tumor associated regulations of endocannabinoids in mouse melanoma models and cancer cell migration assays. The observations were translated to humans by assessing cancer associated changes in circulating endocannabinoids in patients with several types and stages of cancer.

\section{RESULTS}

\section{Endocannabinoid regulation associated with localized malignancies}

Plasma concentrations (Figure 2 top) of ethanolamide endocannabinoids (AEA, OEA and PEA) in mice with a local paw tumor were significantly lower as compared to control mice (t-tests: $p<0.009$ for AEA, $p=0.046$ for OEA and $p=0.007$ for PEA). This was paralleled by the local concentrations in cancerous paw tissue (OEA: $\mathrm{p}=0.003$, PEA: $\mathrm{p}=0.002$ compared with the contralateral paw, Figure 2 middle). In contrast, plasma 2-AG concentrations were increased. While this tendency missed statistical significance $(p=0.063)$, it was significant with respect to local concentrations, i.e., at the tumor site the concentrations of $2-\mathrm{AG}$ were significantly higher than at the control side $(\mathrm{p}<0.001)$.

Endocannabinoid plasma concentrations could be obtained from 298 cancer patients. In age and sex matched subsets of subjects encompassing 42 controls and 44 cancer patients aged $45.3 \pm 5.5$ and $46.2 \pm 5.6$, respectively (t-test for age: $\mathrm{p}=0.44$; equal distribution of sexes; $\chi^{2}-$ test: $\mathrm{p}=0.23)$, comparatively lower concentrations of AEA in patients $(1.1 \pm 0.6 \mathrm{ng} / \mathrm{ml})$ than in the controls $(1.9$ $\pm 0.8 \mathrm{ng} / \mathrm{ml}$ ) were identifiable (Mann-Whitney U-test: $\mathrm{p}$ $<0.001$ ), similarly to the findings in mice. In addition, higher concentrations of $2-\mathrm{AG}$ as seen in mice were also found in this sub-sample of cancer patients (patients: 8.5 $\pm 20.4 \mathrm{ng} / \mathrm{ml}$, controls: $0.9 \pm 0.9 \mathrm{ng} / \mathrm{ml}$, U-test: $\mathrm{p}<0.001$; Figure 2).

\section{Endocannabinoid regulation associated with metastatic cancer}

In the metastatic cancer mouse model, the plasma endocannabinoid concentrations initially increased (Figure $3 \mathrm{~A}$; rm-ANOVA effect of the within-subjects factor "time": AEA $p=0.038$, OEA $p=0.000008$, PEA $\mathrm{p}=0.000002,2-\mathrm{AG} \mathrm{p}<0.000001$; significant differences to baseline depicted in Figure 3). Primary sites of metastases were lung, spleen (Figure 4), peritoneum and lymph nodes. All mice developed metastases at multiple sites. Body weight remained constant up to 3 weeks after tumor cell injection. In the culture wound-healing assay on metastatic cancer OEA exerted dual concentrationdependent effects on tumor cell migration, with most OEA concentrations significantly differing from vehicle (Figure 5). Specifically, low concentrations (0.01 - 1 $\mu \mathrm{M})$ promoted tumor cell migration and wound closure whereas high concentrations $(2-100 \mu \mathrm{M})$ inhibited migration (wound area: rm-ANOVA factor "time": $\mathrm{df}=$ $3,129, \mathrm{~F}=601, \mathrm{p}<0.0001$, factor "OEA concentration": df $=7,120, \mathrm{~F}=15.4, \mathrm{p}<0.0001$, interaction "time" by "OEA concentration": $\mathrm{df}=21,120, \mathrm{~F}=4.99, \mathrm{p}<0.0001)$. At $24 \mathrm{~h}$, effects of OEA on the wound area differed depending on its concentrations $(\mathrm{df}=7,42, \mathrm{~F}=16.8, \mathrm{p}<$ 0.0001; for further statistical details, see Figure 5).

Most of the 298 cancer patients had metastatic cancer $(n=273$ versus $n=25$ without metastases) and the number of metastases at different locations (Table 1) differed significantly between cancer types (configural frequency analysis: $\chi^{2}=127, \mathrm{p}<10^{-6}$ ). The presence of metastases was associated with significantly higher concentrations of ethanolamide endocannabinoids (Figure 3 B), in particular of OEA ( $\mathrm{t}$ - test: $\mathrm{p}<0.001$ $\alpha$-corrected) whereas the similarly directed difference in PEA was only significant at the uncorrected $\alpha$-level $(\mathrm{p}=$ $0.047)$ and that of AEA was not significant $(p=0.111)$. Moreover, the concentrations of PEA and OEA were significantly correlated with the number of metastases (PEA: $\rho=0.165, p=0.004$, OEA: $\rho=0.155, p=0.008$ ). Their concentrations increased with increasing number of metastases (Jonckheere-Terpstra trend test: PEA: $\mathrm{p}=$ 0.005, OEA: $p=0.008)$. In contrast to the ethanolamide endocannabinoids, concentrations of $1+2-\mathrm{AG}$ were not influenced by the number of metastases $(p=0.4)$.

\section{DISCUSSION}

Endocannabinoids are involved in the regulation of several physiological systems that are involved in tumor development and tumor growth [6] as demonstrated by a disturbance of endocannabinoids in cancer in general, and specifically in metastatic cancer [4-7]. We showed a downregulation of ethanolamide endocannabinoids following local cancer induction in mice translated into 
cancer patients. This decrease and the reciprocally directed increase in 2-AG might be interpreted as reflecting a tumor-evoked alteration of the microenvironment that possibly favors tumor growth. In mice plasma ethanolamide endocannabinoids re-raised during spreading of the cancer cells and 2-AG kept increasing. The increase was evoked in mice by intravenous injection of the tumor cells directly initiating metastatic disease.
The role of metastases translated into differences in circulating ethanolamide endocannabinoids in patients, in whom endocannabinoids increased with the number of metastases.

Since plasma concentrations of endocannabinoids may point at an intact communication between brain, immune system, hormones, fat and muscle tissue [19], the present investigation suggested that this

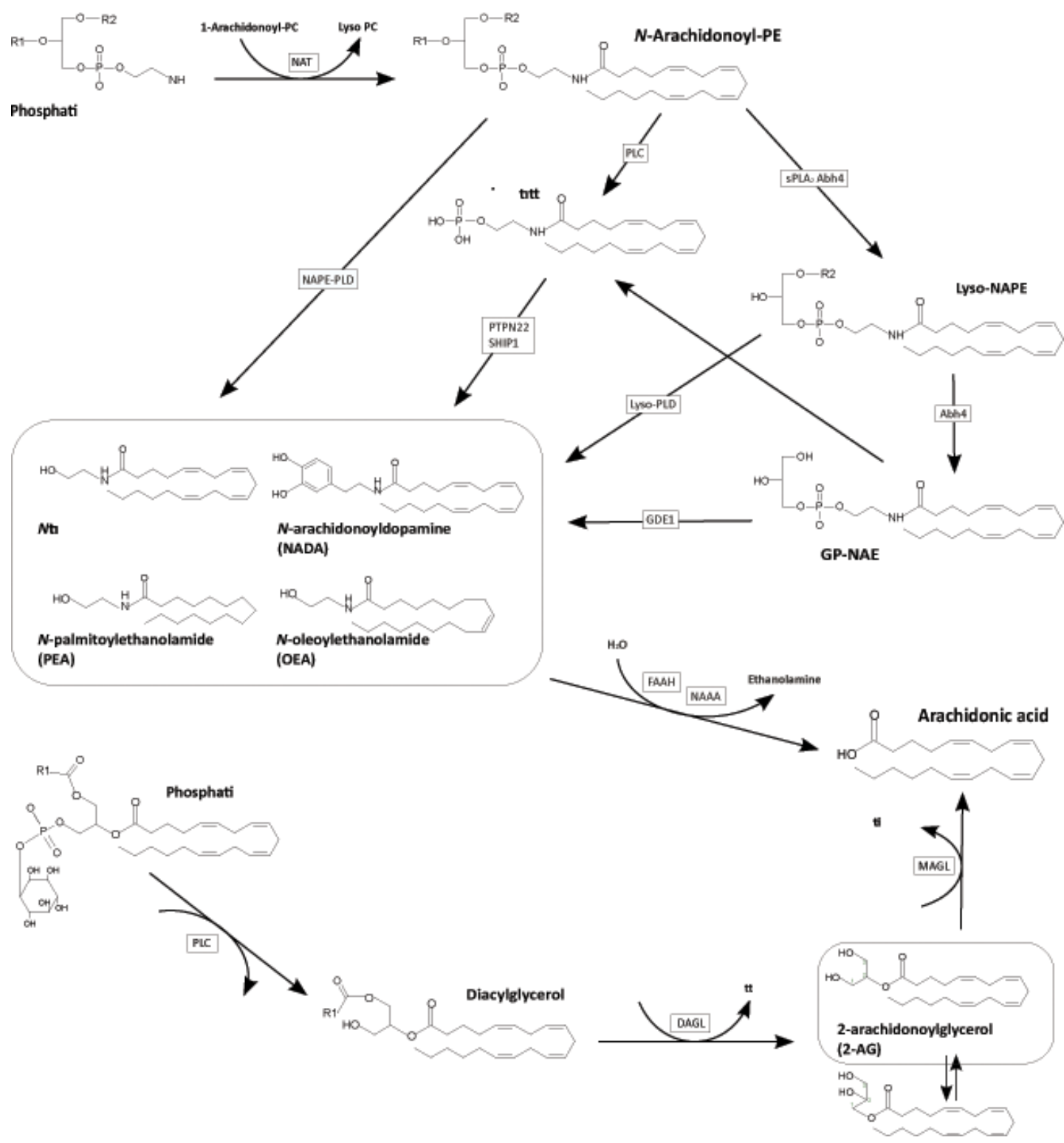

Figure 1: Pathways for the synthesis and degradation of $\mathrm{N}$-actetylethanolamines (NAE) and 2-arachidonoylglycerol (2AG). The first reaction of the NAE-synthesis is the N-acylation of phosphatidylethanolamine (PE), which is catalyzed by $\mathrm{N}$-acyltransferase (NAT). The most important second step is a phospholipase (PDL)-type hydrolysis of the resultant N-acylethanolamine-phosphatidylethanolamine (NAPE-PE) by the NAPE-PLD leading to the formation of the NAEs, N-arachidonoylethanolamide, N-palmitoylethanolamide, and $\mathrm{N}$-oleoylethanolamide and a related substance, $\mathrm{N}$-arachidonoyldopamine (NADA). Other suggested pathways are a two-step process involving a PLC-like hydrolysis of N-arachidonoyl-PE with subsequent dephosphorylation of anandamide phosphate by PTPN22 and the double-deacylation of NAPE by $\alpha / \beta$-hydrolase 4 (Abh4) with subsequent hydrolysis of the phosphodiester bond of the resultant glycerophospho-NAE (GP-NAE) by glycerophosphodiester phosphodiesterase 1 (Gde1). The major pathway for the biosynthesis of 2-AG involves sequential hydrolysis of arachidonic acid-containing inositol phospholipids by PLC and diacylglycerol lipase (DAGL). The degradation of the NAEs as well as 2-AG is catalyzed by the N-acylethanolamine-hydrolyzing amidase (NAAA), fatty acid amide hydrolase (FAAH) and monoacylglycerol lipase (MAGL), respectively, and results in arachidonic acid. 

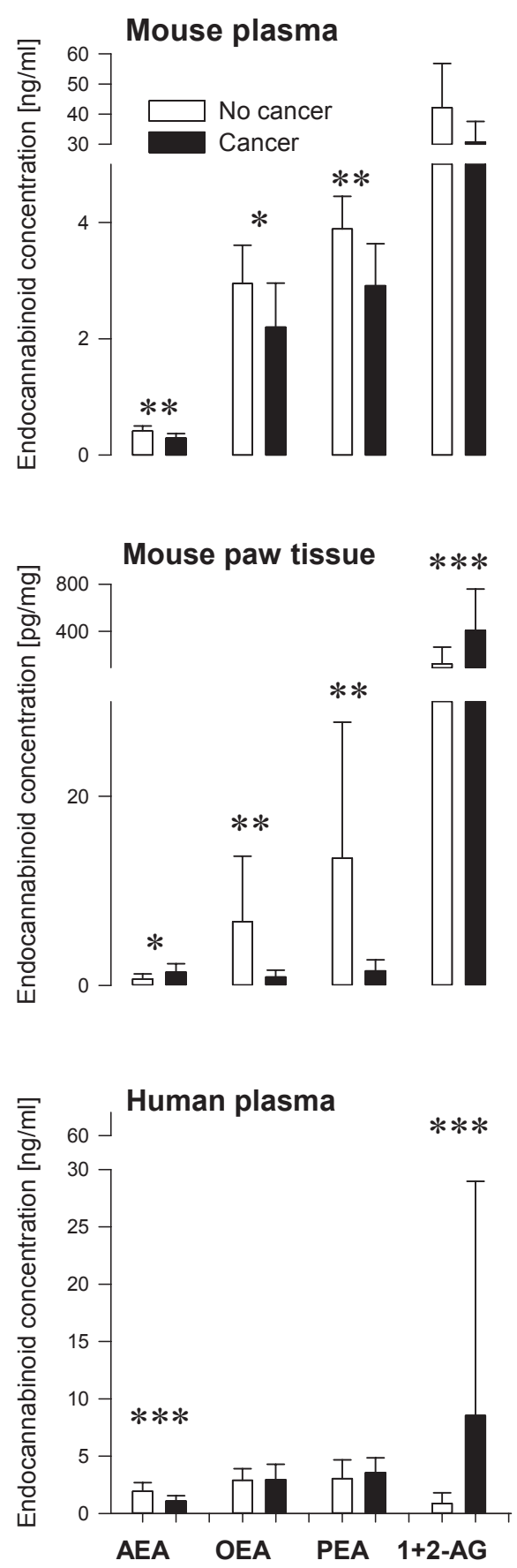

Figure 2: Plasma and tissue concentrations (means \pm SD) of endocannabinoids in plasma of mice (top) and humans (bottom) and in the tumor environment of a local paw tumor in mice (middle). B16 mouse melanoma cells were injected into the left paw fat pad tissue. Plasma and paw tissue samples were obtained 14 days after tumor cell injection. In control mice, cell suspension medium without tumor cells was injected. Dissected tissue samples contained the tumor and immediately surrounding tissue. $\mathrm{n}=8-9$ mice for plasma, $\mathrm{n}=18$ mice for tissue. Human data was assessed crosssectionally in aged and sex matched subsamples of patients $(\mathrm{n}=$ $44)$ and controls $(n=42)$ ). Asterisks indicate significant group differences between (t-tests: ${ }^{*}: \mathrm{p}<0.05,{ }^{* *}: \mathrm{p}<0.01,{ }^{* *}: \mathrm{p}<$ $0.001)$. balance is deranged in cancer to a degree measurable in plasma despite many influences contributing to circulating endocannabinoids. Those include their production in peripheral tissues and the brain and their degradation depending on the functioning of several enzymes such as the fatty acid amide hydrolase (FAAH), the monoacylglycerol lipase (MAGL), the palmitoylethanolamide-preferring acid amidase and cyclooxygenases [23], lipoxygenases and cytochrome P450 enzymes [24]. It is conceivable that the metabolism of ethanolamide endocannabinoids was increased in cancer. For example, FAAH is known to be upregulated
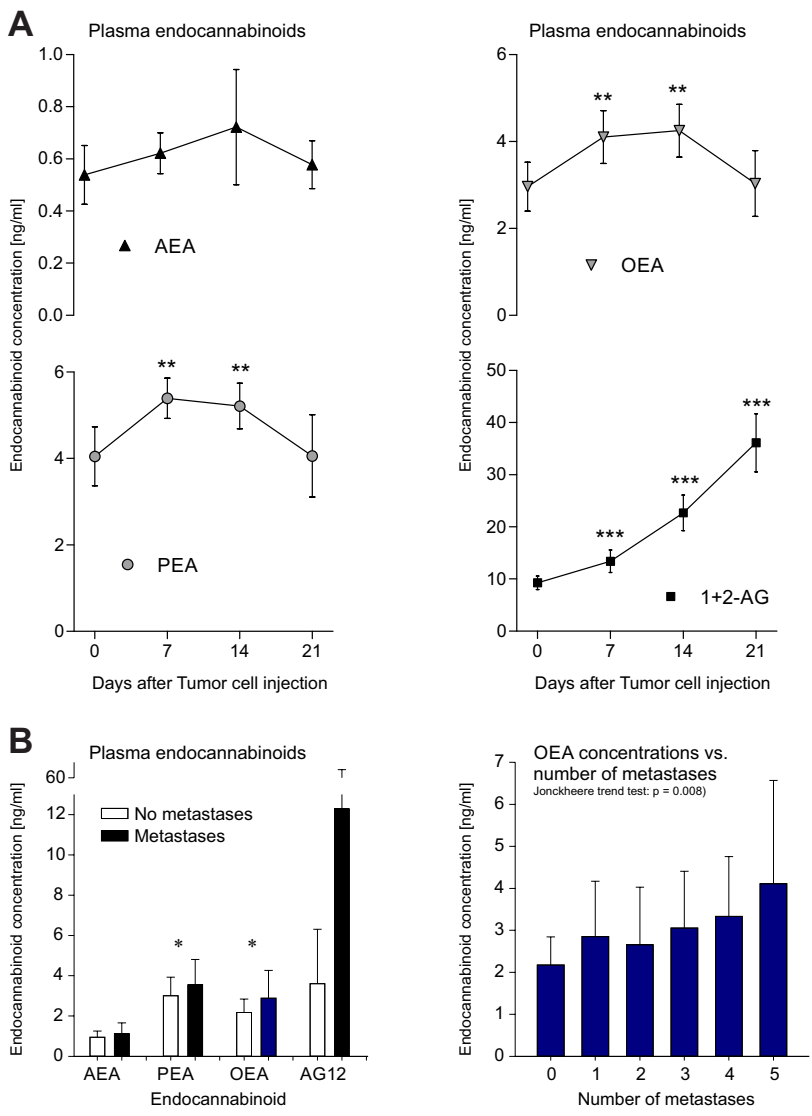

Figure 3: Changes in endocannabinoid plasma concentrations associated with metastases: A: Plasma concentrations (mean $\pm \mathrm{SD}$ ) of endocannabinoids in metastatic mouse B16 mouse melanoma. Cells were injected via the tail vein and metastases were identified on the basis of the melanin production. They developed in lung, spleen, peritoneum and lymph nodes. Plasma samples were taken at the indicated times before and after tumor cell injection. B: Plasma endocannabinoid concentrations in cancer patients. Increased ethanolamide endocannabinoid plasma concentrations in the presence of metastases resembled alterations in mice (left). Asterisks indicate significant group differences between groups (t-tests after significant ANOVA: *: $\mathrm{p}<0.05, * *$ : $<<0.01, * * *$ : $\mathrm{p}<0.001$ Bonferroni $\alpha$-corrected (with exception of PEA)). Moreover, the concentrations of OEA (and PEA) increased significantly with increasing number of metastases (JonckheereTerpstra trend test: PEA: $\mathrm{p}=0.005$, OEA: $\mathrm{p}=0.008$ ). 
Table 1: Patients' demographics, the actual Roman Numeral Staging and the number of metastases, grouped per cancer diagnosis.

\begin{tabular}{|c|c|c|c|c|c|c|c|c|c|c|c|c|}
\hline & & $\begin{array}{l}\text { Urologic / } \\
\text { Prostatic } \\
\text { cancer }\end{array}$ & $\begin{array}{l}\text { Breast } \\
\text { cancer }\end{array}$ & Lung cancer & $\begin{array}{c}\text { Gastroin- } \\
\text { testinal } \\
\text { tumors }\end{array}$ & $\begin{array}{l}\text { Hematolog- } \\
\text { ical malig- } \\
\text { nancies }\end{array}$ & $\begin{array}{l}\text { Pancreatic } \\
\text { cancer }\end{array}$ & $\begin{array}{l}\text { Gynecolog- } \\
\text { ical cancer }\end{array}$ & Skin cancer & $\begin{array}{c}\text { Other } \\
\text { malignan- } \\
\text { cies }\end{array}$ & All & $\begin{array}{l}\text { Statistical } \\
\text { compari- } \\
\text { sons }\end{array}$ \\
\hline \multicolumn{2}{|l|}{$\mathbf{N}$} & 42 & 57 & 48 & 79 & 18 & 30 & 15 & 6 & 9 & 304 & \\
\hline \multicolumn{2}{|c|}{ Men/ women [n] } & $39 / 3$ & $1 / 56$ & $28 / 20$ & $46 / 33$ & $9 / 9$ & $15 / 15$ & $0 / 15$ & $4 / 2$ & $5 / 4$ & $147 / 157$ & $0.00015^{a}$ \\
\hline \multicolumn{2}{|c|}{ Age [yrs] } & $67.5 \pm 11.9$ & $62.2 \pm 9.3$ & $63.9 \pm 10.3$ & $64.5 \pm 10.7$ & $64.8 \pm 15.6$ & $66.3 \pm 7.3$ & $66.9 \pm 6.2$ & $53 \pm 13.6$ & $61.9 \pm 9.9$ & $64.4 \pm 10.6$ & $0.049^{b}$ \\
\hline \multicolumn{2}{|c|}{ Weight [kg] } & $79.5 \pm 15$ & $70.3 \pm 15$ & $73.6 \pm 17.1$ & $72.2 \pm 15.4$ & $78.2 \pm 17.5$ & $66.6 \pm 13.6$ & $70.5 \pm 15.7$ & $77.5 \pm 14.4$ & $72 \pm 17.2$ & $72.9 \pm 15.8$ & $0.03^{b}$ \\
\hline \multicolumn{2}{|c|}{ BMI } & $25.6 \pm 4.8$ & $26.4 \pm 5.1$ & $25 \pm 4.6$ & $24.5 \pm 4.2$ & $26.5 \pm 5.1$ & $23 \pm 4.1$ & $26 \pm 5.5$ & $26.8 \pm 5.6$ & $24 \pm 5.1$ & $25.2 \pm 4.7$ & $0.053^{b}$ \\
\hline \multicolumn{2}{|c|}{ Former/actual smokers [n] } & $5 / 4$ & $3 / 8$ & $8 / 22$ & $8 / 8$ & $4 / 0$ & $7 / 6$ & $1 / 1$ & $0 / 1$ & $1 / 0$ & $37 / 50$ & $0.000007^{c}$ \\
\hline \multicolumn{2}{|c|}{$\begin{array}{l}\text { Time since cancer diagno- } \\
\text { sis [month] }\end{array}$} & $61.7 \pm 44$ & $\begin{array}{c}106.5 \pm \\
84.1\end{array}$ & $17.5 \pm 20.4$ & $43.5 \pm 44.1$ & $34.6 \pm 36.4$ & $16.9 \pm 25$ & $55.3 \pm 34.5$ & $48.5 \pm 45.8$ & $66 \pm 92.7$ & $51.9 \pm 59.3$ & $<0.00001^{b}$ \\
\hline \multicolumn{2}{|c|}{ Karnofsky status } & $75.2 \pm 16.3$ & $74.6 \pm 16$ & $76.3 \pm 15.2$ & $77.2 \pm 14.8$ & $79.4 \pm 18.3$ & $78.3 \pm 15.6$ & $81.3 \pm 14.1$ & $90 \pm 16.7$ & $73.3 \pm 21.8$ & $76.9 \pm 15.8$ & $0.414^{b}$ \\
\hline \multirow{13}{*}{ 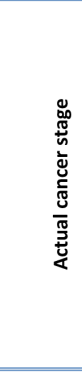 } & 1 & 2 & 1 & 0 & 0 & 0 & 0 & 0 & 0 & 0 & 3 & \multirow{13}{*}{-} \\
\hline & la & 0 & 0 & 2 & 0 & 0 & 0 & 1 & 0 & 1 & 4 & \\
\hline & $\mathrm{lb}$ & 0 & 0 & 0 & 0 & 0 & 1 & 0 & 0 & 0 & 1 & \\
\hline & II & 1 & 0 & 1 & 0 & 0 & 0 & 0 & 0 & 0 & 2 & \\
\hline & Ila & 0 & 2 & 1 & 0 & 1 & 4 & 0 & 0 & 1 & 9 & \\
\hline & $\mathrm{Ilb}$ & 0 & 3 & 4 & 0 & 0 & 5 & 0 & 0 & 0 & 12 & \\
\hline & III & 1 & 0 & 0 & 0 & 7 & 2 & 0 & 0 & 0 & 10 & \\
\hline & IIIa & 0 & 1 & 1 & 10 & 0 & 0 & 1 & 0 & 0 & 13 & \\
\hline & $\mathrm{IIIb}$ & 1 & 0 & 8 & 4 & 0 & 0 & 1 & 1 & 0 & 15 & \\
\hline & IV & 37 & 50 & 31 & 57 & 4 & 17 & 12 & 5 & 7 & 220 & \\
\hline & $\begin{array}{ll}\mathrm{IVa} \\
\end{array}$ & 0 & 0 & 0 & 4 & 0 & 0 & 0 & 0 & 0 & 4 & \\
\hline & $\mathrm{IVc}$ & 0 & 0 & 0 & 3 & 0 & 0 & 0 & 0 & 0 & 3 & \\
\hline & n.a. & 0 & 0 & 0 & 1 & 6 & 1 & 0 & 0 & 0 & 8 & \\
\hline \multirow{7}{*}{ 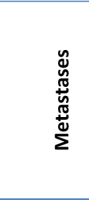 } & Liver & 9 & 22 & 10 & 43 & 2 & 13 & 6 & 0 & 5 & 110 & \multirow{7}{*}{$<0.000001^{\circ}$} \\
\hline & Bone & 23 & 34 & 9 & 7 & 9 & 0 & 1 & 0 & 2 & 85 & \\
\hline & CNS & 2 & 6 & 6 & 2 & 0 & 0 & 0 & 2 & 0 & 18 & \\
\hline & Lung & 13 & 17 & 20 & 29 & 1 & 3 & 2 & 2 & 5 & 92 & \\
\hline & Lymphatic & 21 & 39 & 40 & 64 & 6 & 21 & 11 & 5 & 3 & 210 & \\
\hline & Other & 7 & 14 & 14 & 23 & 2 & 8 & 10 & 2 & 2 & 82 & \\
\hline & All & 75 & 132 & 99 & 168 & 20 & 45 & 30 & 11 & 17 & 597 & \\
\hline
\end{tabular}

a: Significances are given according to $\chi^{2}$ statistical comparisons among cancer types. ${ }^{b}:$ In the case of ANOVA, the main effect of the factor "cancer diagnosis" is given. ${ }^{c}$ : The numbers of never smokers, former smokers, and actual smokers were compared among cancers. ${ }^{\mathrm{d}}$ : results of a configural frequency analysis.

in prostate, pancreatic, colon and breast cancer [25-28]. In addition, COX-2 is also known to be upregulated in various types of cancer [29]. As some COX-2 inhibitors reduce the risk for colon cancer, which cannot entirely be explained by inhibition of prostaglandin synthesis [30], an effect mediated via the endocannabinoid system appears possible and would fit to the present observations, i.e., a reduction of oxidative degradation of ethanolamide endocannabinoids might contribute to the cancer protective effects of COX-2 inhibition. Similarly, substances that reduce the activity of FAAH such as flurbiprofen [31] and thus increase endocannabinoid concentrations exert antiproliferative actions $[32,33]$. In contrast to ethanolamide endocannabinoids, 2-AG may promote tumor invasiveness. It was suggested that this occurs by rapid metabolism to 12-HETE by 12/15 lipoxygenases, which, at least in prostate cancer, promotes tumor growth [34]. In addition, MAGL hydrolyzes 2-arachidonoylglycerol to

\section{Lung}

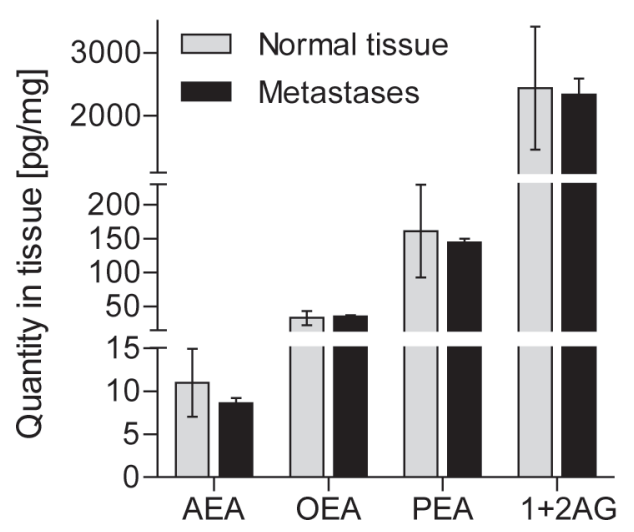

\section{Spleen}

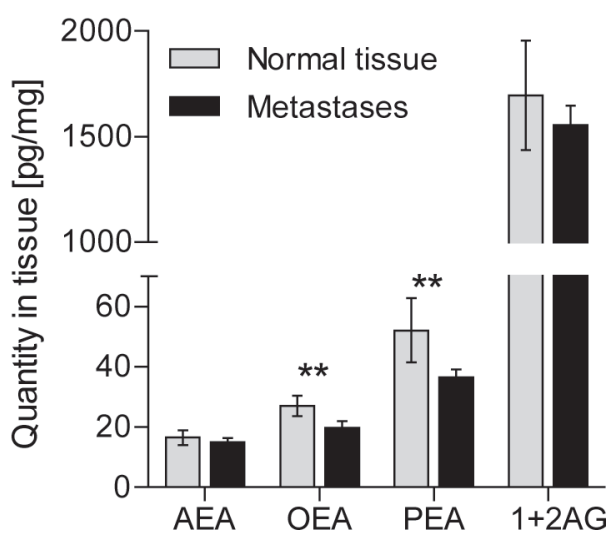

Figure 4: Tissue concentrations (mean \pm SD) of endocannabinoids in metastatic mouse B16 mouse melanoma. Cells were injected via the tail vein and metastases were identified on the basis of the melanin production. They developed in lung, spleen and lymph nodes. Metastases and corresponding control tissue samples were dissected at 4 weeks ( $\mathrm{n}=10$ mice for plasma, 5-8 for tissue). Asterisks indicate significant differences versus baseline (plasma) or metastasis versus non-cancerous corresponding tissues (t-tests after significant ANOVA, $\mathrm{p}<0.05)$. 


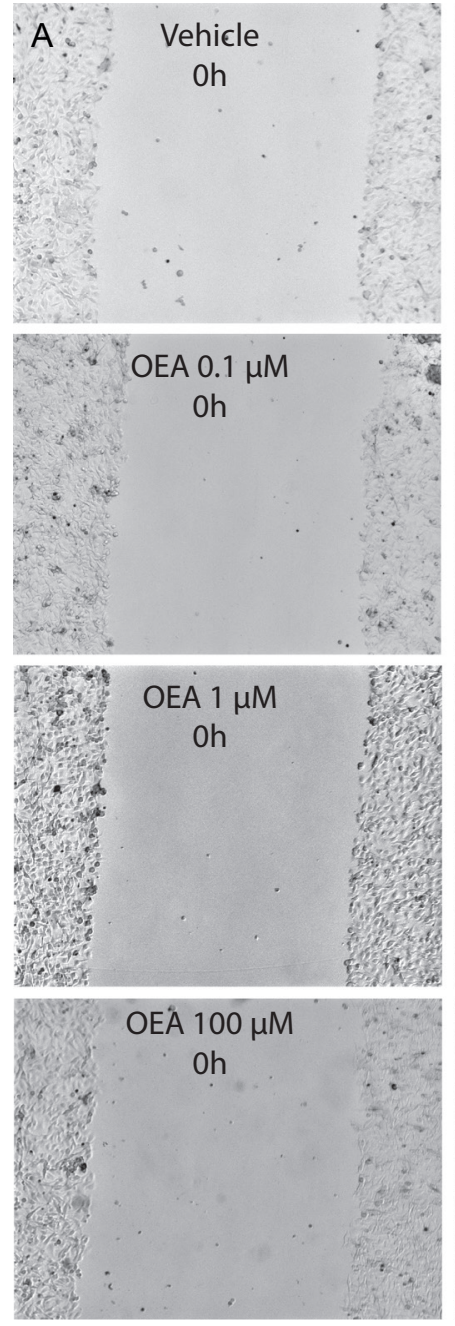

B

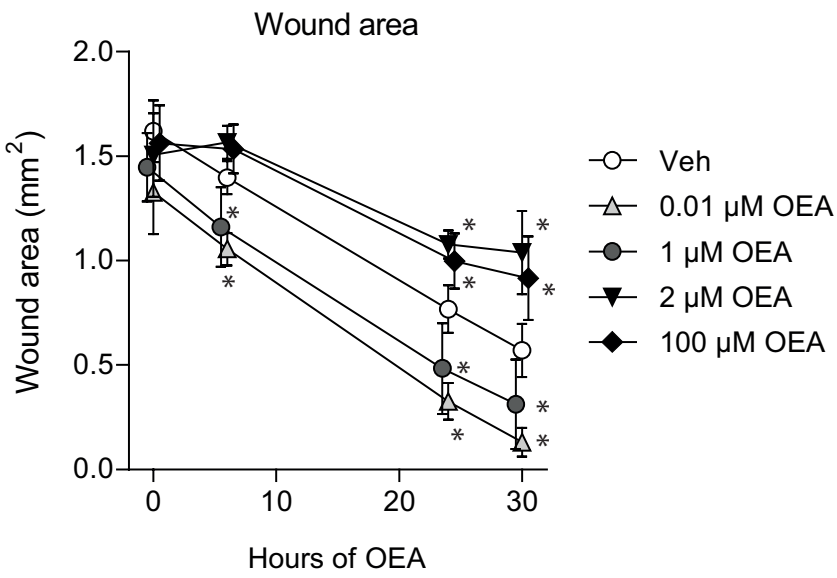

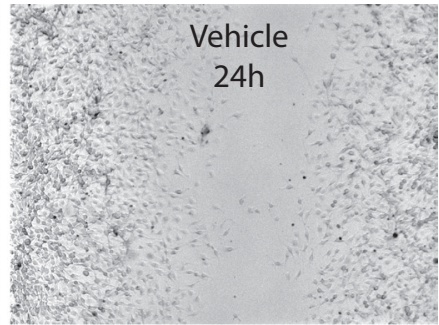
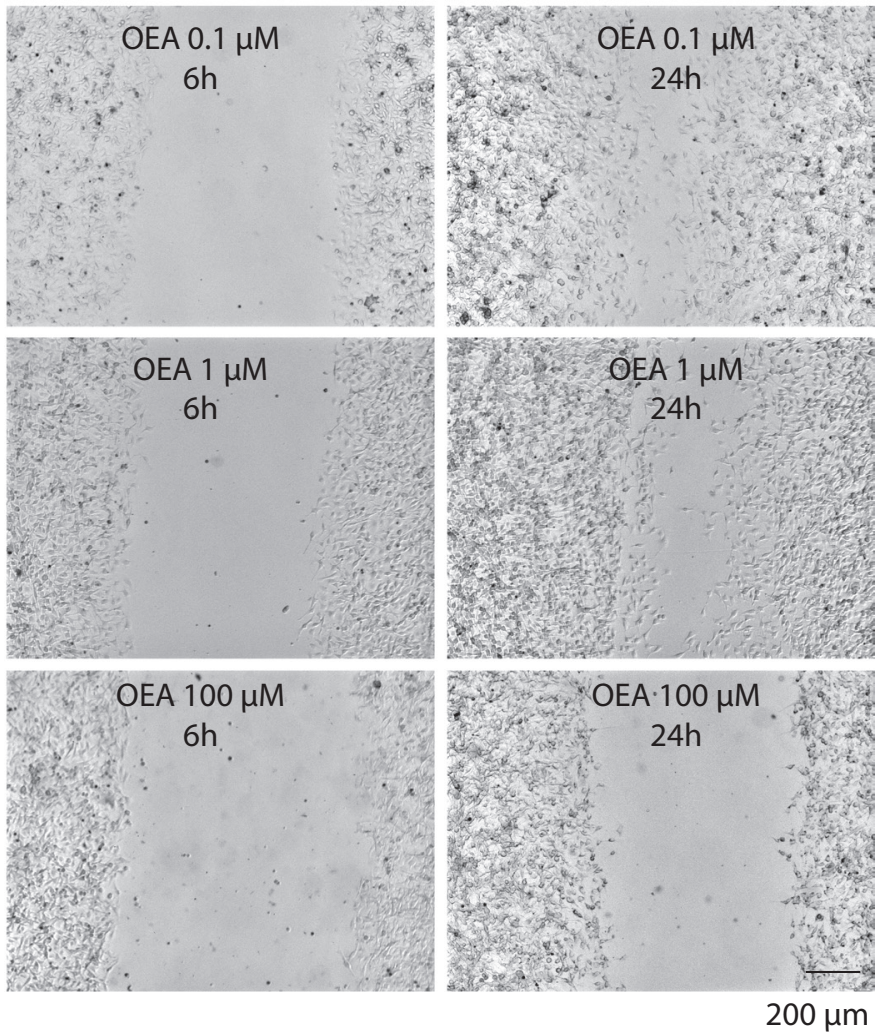

C

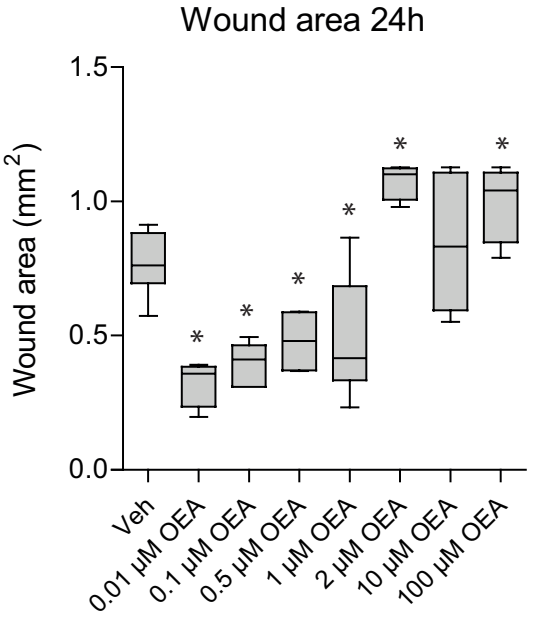

Figure 5: Effects of OEA on B16 cell migration and wound closure in culture. Sub-confluent B16 cultures were scratched with a pipet tip causing ca. $1 \mathrm{~mm}$ wide wounds. Images were captured directly after scratching $(0 \mathrm{~h})$ and at 6,24 and $30 \mathrm{~h}$. The wound area was analyzed. A: Examples of the culture wound in vehicle and OEA treated cultures. B: Quantitative analysis of the time course of the wound area (mean $\pm \mathrm{SD}$ ). C: Box plots of the wound areas of vehicle and OEA treated cultures at $24 \mathrm{~h}$. The boxes show the $25^{\text {th }}-75^{\text {th }}$ quantiles and the whiskers the $10^{\text {th }}-90^{\text {th }}$. The line is the median. Asterisks indicate statistically significant differences versus vehicle treated cultures, $\mathrm{p}<$ 0.05. For comparison, human plasma concentrations were in the range of $5-20 \mathrm{nM}$, whereas paw concentrations in control animals ranged from 10 - $50 \mathrm{pmol} / \mathrm{mg}(\sim 10-50 \mu \mathrm{M})$. 
generate an arachidonate precursor pool for prostaglandins [35], which also promote certain types of cancer [36].

Decreases of circulating endocannabinoid concentrations in patients with metastatic cancer were less pronounced than in patients with non-metastatic cancer. The sources of these endocannabinoids may be the spreading tumor cells themselves. Alternatively, activated immune cells may release the endocannabinoids when they are stimulated by circulating viable and dying tumor cells [37]. The observed time course of plasma endocannabinoid concentrations in the metastatic mouse model suggests an initial immune activation by large numbers of circulating tumor cells, which was followed by a state of anergy or immune cell redistribution as soon as the metastases were established. In the cross-sectional human metastatic cancer data, the association of OEA and PEA concentrations with the number of metastases hints at similar mechanisms as in mice. An involvement of endocannabinoids in cancer dissemination was also supported by the in-vitro observations. In particular low OEA concentrations, which were in the range of those observed in human and mouse plasma, promoted cell migration, for which $\mathrm{G}_{\mathrm{i}}-$ or $\mathrm{G}_{\mathrm{q}} / 11$ protein mediated activation of Erk pathways [38] resembling other $\mathrm{G}_{i}$ - or $\mathrm{G}_{\mathrm{q}} / 11$ activators [39] or a specific effect through OEAtargeted G-protein coupled receptors including GPR55 and GPR119 may be responsible. The inhibition of tumor cell migration at high OEA concentrations, by contrast, possibly owes to the activation of PPARs [40, 41] that are known targets of OEA [3]. In the healthy mouse paw tissue OEA concentrations were in the range of these inhibitory concentrations but concentrations in vitro cannot be directly transferred to the in vivo situation because monoculture conditions do not picture the microenvironment and immune-tumor interactions. Nevertheless, in vitro data support the idea that decreasing endocannabinoid levels favor tumor growth and spreading.

The duality of the OEA effects adds to the controversy about cannabinoid actions on tumor growth. From previous studies it may be inferred that endocannabinoids generally have dual functions in cancer because of their complex effects on tumor cells, endothelial cells and immune cells so that the outcome of endocannabinoid changes likely depends on the local composition of cannabinoid receptors, orphan G-protein coupled receptors and nuclear receptors. For example, GPR55 promotes tumor cell proliferation and angiogenesis [42], $\mathrm{CB}_{1}$ inhibits tumor growth and $\mathrm{CB}_{2}$ likely promotes tumor-tolerant immune cells. However, opposite effects such as tumor killing by $\mathrm{CB}_{2}$ agonists have also been observed [43]. In addition, effects depend on the endocannabinoid concentrations as shown by the in-vitro data. The re-raise of OEA upon metastasis and the correlation of OEA plasma concentrations with the number of metastases may be due to a redistribution or polarization of the immune cells and reflect an attempt to attack the tumor cells. Compared with the in vitro OEA concentrations needed to block migration, plasma OEA levels remained low. Hence, the re-raise of OEA in metastatic cancer may rather indicate frustrate immune stimulation, which was stronger with more metastases but does not indicate successful tumor cell killing.

A further finding of this study was that in addition to OEA, high plasma concentrations of 2-AG were associated with tumor progression and possibly favor it. Previously reported 2-AG values in plasma ranged between 0.4 and $7.5 \mathrm{ng} / \mathrm{ml}$ [44], which corresponds to the concentrations measured in the plasma of the present healthy subjects, up to $20 \mathrm{ng} / \mathrm{mL}$ [45] in obese subjects. In the present subjects, circulating $1+2-\mathrm{AG}$ concentrations were weakly positively correlated with the patients' body mass index (Spearman's $\left.\rho^{2}: 0.031, p=0.001\right)$. Therefore, weight loss might be associated with a "readjustment" of individual normal levels but body weight does not explain the high 1+2-AG observed in metastatic cancer, which rather reduces body weight (presently $72 \pm 21 \mathrm{~kg}$ versus $74 \pm 15 \mathrm{~kg}$ in patients without metastases).

Considering the present observations of several regulatory consequences on endocannabinoids during cancer, the shift in endocannabinoid plasma profiles might be a candidate biomarker to assess disease progression. In particular, the time courses of endocannabinoid plasma concentrations during tumor cell spreading and establishment of metastases in mice suggested such progression dependency. To test the utility of the human data as a biomarker, endocannabinoid concentrations were submitted to binary logistic regression to identify the cutoff concentration where the probability of metastases was greater than chance but this failed, and on the basis of endocannabinoid concentrations, neither alone nor combined, a prediction of the existence of metastases was not achieved. Thus, circulating endocannabinoid concentrations reflect cancer associated changes but due to the complexity of cannabinoid regulations [19], crosssectionally assessed endocannabinoid concentrations cannot be exploited as a sensitive biomarker. This does not necessarily extent to longitudinal observations during cancer progression, for which the mouse data provides conceptual support.

The endocannabinoid system was subject to cancerassociated regulations to an extent that led to measurable changes in circulating endocannabinoid levels. In particular, the present analyses showed that various tumors and metastases are associated with reduced circulating ethanolamide endocannabinoids. The changes in circulating endocannaboinds probably do not yet qualify as a biomarker for cancer progression. Nevertheless, given the various major influences on circulating endocannabinoids, the fact that cancer-associated changes were detectable at a statically significant level may reflect the importance of the endocannabinoid system as a factor of cancer progression. 


\section{METHODS}

\section{Animal and molecular study}

\section{Mouse melanoma model}

The animal experiments were approved by the regional Ethics Committee for animal research (Darmstadt, Germany) and were in line with the European and German regulations for animal research, in particular the rules of cancer research. Male 8 - 12 weeks-old C57BL/6J mice were used. The mice had free access to food and water, were maintained in climate-controlled rooms at a 12-h light-dark cycle. Mouse melanoma cells (ATCC B16) originating from C57BL/6J mice were grown in 1:1 Dulbecco's modified Eagle medium (DMEM) with $10 \%$ supplemental fetal bovine serum and $1 \%$ penicillin/ streptomycin. The cells were kept in an incubator at 37 ${ }^{\circ} \mathrm{C}, 95 \%$ humidity and $5 \% \mathrm{CO}_{2}$ atmosphere, harvested by trypsinization, suspended in cell culture medium and injected subcutaneously into the plantar pad of the left hind paw ( $1 \times 10^{4}$ cells in $20 \mu \mathrm{l}$ of culture medium) under $1.5-2 \%$ isoflurane anesthesia. Cell culture medium without tumor cells was injected in control mice. For induction of metastatic cancer, B16 cells were suspended in $0.9 \%$ saline and injected through the tail vein $\left(1 \times 10^{5}\right.$ cells in $50 \mu \mathrm{l}$ ) after taking baseline plasma samples. Eight to nine mice per group were used for plasma samples and 18 mice for paw tissue.

Fourteen days (paw) or three weeks (metastatic) after tumor cell injection mice were finally anaesthetized with isoflurane and blood samples were collected by cardiac puncture in heparinized tubes. After intravenous tumor cell injection additional samples were collected during the course of the disease by puncturing the retroorbital plexus. After centrifugation, plasma was frozen on dry ice and stored at $-80{ }^{\circ} \mathrm{C}$ pending analysis. The subcutaneous fat tissue of the paws with the B16 tumor or respective tissue from control mice was dissected, rapidly frozen on dry ice and stored at $-80^{\circ} \mathrm{C}$. In metastatic cancer the number and localization of metastases were assessed during necropsy.

\section{Cancer cell migration assay}

To assess the effects of OEA on tumor cell migration a standard scratch assay [20] was employed. B16 mouse melanoma cells $\left(5 \times 10^{5}\right.$ cells) were seeded in 6-well culture plates and grown to sub-confluence (90\%). Cultures were then scratched with a blue pipet tip. Just before scratching the culture OEA $(0.01,0.1,0.5,1,2$, 10 or $100 \mu \mathrm{M}$ in $2 \mu 1$ ethanol) was added to the culture medium (DMEM without FBS) and thoroughly mixed. Control cultures received the respective volume of vehicle. Images of the wound were captured with an inverted Zeiss microscope (Axiovert) at times 0, 6, 24 and $30 \mathrm{~h}$. Images were analyzed using the Autmess modul of Axiovision (Zeiss) in terms of the wound area, relative to the area at $0 \mathrm{~h}$, and in terms of the number of cells within the wound area.

\section{Human data}

Human data was available from an observational cross-sectional investigation of 304 cancer patients (147 men, 157 women, aged $32-87$ years, Table 1) consecutively recruited from outpatients $(\mathrm{n}=286)$ and inpatients $(\mathrm{n}=18)$ of the Department of Hematology and Oncology, Nordwest Hospital, Frankfurt am Main, Germany. The Declaration of Helsinki on Biomedical Research Involving Human Subjects was adhered to and data and blood collection was approved by the Ethics Committees of the Medical Faculty of the Goethe University and of the Landesärztekammer Hessen, Frankfurt am Main, Germany. Informed written consent from each participating subject had been obtained (Table 1). Tumor staging at diagnosis was recorded with the TNM Classification of Malignant Tumors by the Union for Cancer Control (UICC at http://www.uicc.org/tnm). Venous blood samples were collected to $\mathrm{Na}^{+}$-EDTA tubes and centrifuged at 3,000 rpm for $10 \mathrm{~min}$. Plasma was frozen at $-80^{\circ} \mathrm{C}$ pending analysis. Aged and sex matched samples for comparative analyses of endocannabinoid concentrations were drawn from a cohort of 300 healthy subjects in total ( 99 men, 201 women, aged 18 - 57 years), enrolled in the Occupational Health Service ambulance at the University Hospital of Frankfurt am Main, Germany. Enrollment and sample acquisition had been approved by the local Ethics committee, and informed written consent from each participating subject had been obtained.

\section{Analysis of endocannabinoid concentrations}

Concentrations of AEA, PEA, 1- and 2-AG and OEA were quantified by means of liquid chromatography tandem mass spectrometry assays as described elsewhere [21]. Briefly, plasma samples were spiked with the internal standards and liquid-liquid extracted. After evaporation, samples were reconstituted with $50 \mu \mathrm{L}$ of acetonitrile and injected into the LC-MS/MS system. Separation of the analytes was carried out under gradient conditions using a Luna C18 column. Precursor-to-product ion transitions of $m / z 346 \rightarrow 259$ for AEA, $m / z 354 \rightarrow 267$ for AEA-d $\mathrm{d}_{8}$, $m / z 298 \rightarrow 268$ for PEA, $m / z 302 \rightarrow 272$ for PEA-d ${ }_{4}, m / z$ $377 \rightarrow 303$ for 2 -AG and 1 -AG, $m / z 382 \rightarrow 303$ for 2 -AG$\mathrm{d}_{5}$ and $1-\mathrm{AG}-\mathrm{d}_{5}, m / z 324 \rightarrow 86$ for OEA, and $m / z 326 \rightarrow 86$ 
for OEA- $d_{2}$ were used for quantitation. Concentrations of the calibration standards, quality controls and unknowns were evaluated by Analyst software (version 1.5; AB Sciex, Darmstadt, Germany). Variations in accuracy and intra-day and inter-day precision $(\mathrm{n}=6$ for each concentration, respectively) were $<15 \%$ over the range of calibration. In an acidic environment, 2-AG undergoes acyl migration converting it to its more stable regio-isomer 1-AG [22] (Figure 1 bottom right). Therefore, statistical analyses were done on the sum of their concentrations. The lower limits of quantification were $0.1 \mathrm{ng} / \mathrm{ml}$ for anandamide, $0.25 \mathrm{ng} / \mathrm{ml}$ for $1-\mathrm{AG}$ and $2-\mathrm{AG}$, and $0.5 \mathrm{ng} /$ $\mathrm{ml}$ for PEA and OEA.

\section{Statistics}

Endocannabinoid concentrations were compared between groups or matched subsamples of groups using analyses of variance (ANOVA), t-tests or Mann-Whitney $\mathrm{U}$ tests according to the data distribution. Trends were analyzed using the Jonckheere-Terpstra trend test. Further analyses consisted of correlations (Spearman's $\rho$ ) and $\chi^{2}$ statistics. The wound area from the cell migration assay was analyzed by means of repeated-measures ANOVA, with within-subjects factors "time" and between-subjects factors "OEA concentration", and for the $24 \mathrm{~h}$ observations by means of ANOVA with the between-subjects factor "OEA concentration". T-tests were used for post-hoc comparisons against vehicle. The $\alpha$ level was set at 0.05 and corrected for multiple testing (Bonferroni). Statistics were done with the SPSS software package (version 21 for Linux, IBM SPSS Inc., Chicago, USA).

\section{ACKNOWLEDGMENT}

We thank Thekla Myrczek, Annett Häussler and Sandra Labocha for technical assistance.

\section{Conflict of Interest statement}

The authors have declared that no competing interests exist.

\section{Funding}

This work was supported by the European Graduate School GRK757 (JL and GG) providing personnel funding, by the Deutsche Forschungsgemeinschaft (DFG GE 695/3-1 (GG) and DFG Lo 612/10-1 (JL) providing funding for materials for the concentration analyses, and by DFG CRC 1039/A3 (IT) providing funding of the animal and cell culture experiments. The funders had no role in study design, data collection and analysis, decision to publish, or preparation of the manuscript.

\section{Author Contributions}

Conceived and designed the experiments: EJ, GG, IT, JL. Performed the experiments: SS, NF, GP, KZ, KS. Analyzed the data: SS, KS, IT, JL. Contributed reagents/ materials/analysis tools: GG, IT. Wrote the paper: CW, IT, JL.

\section{REFERENCES}

1. Matsuda LA, Lolait SJ, Brownstein MJ, Young AC and Bonner TI. Structure of a cannabinoid receptor and functional expression of the cloned cDNA. Nature. 1990; 346(6284):561-564.

2. Yin H, Chu A, Li W, Wang B, Shelton F, Otero F, Nguyen DG, Caldwell JS and Chen YA. Lipid G protein-coupled receptor ligand identification using beta-arrestin PathHunter assay. J Biol Chem. 2009; 284(18):12328-12338.

3. O'Sullivan SE. Cannabinoids go nuclear: evidence for activation of peroxisome proliferator-activated receptors. Br J Pharmacol. 2007; 152(5):576-582.

4. Di Marzo V, Melck D, Orlando P, Bisogno T, Zagoory O, Bifulco M, Vogel Z and De Petrocellis L. Palmitoylethanolamide inhibits the expression of fatty acid amide hydrolase and enhances the anti-proliferative effect of anandamide in human breast cancer cells. Biochem J. 2001; 358(Pt 1):249-255.

5. Grimaldi $\mathrm{C}$ and Capasso A. The endocannabinoid system in the cancer therapy: an overview. Current medicinal chemistry. 2011; 18(11):1575-1583.

6. Guindon J and Hohmann AG. The endocannabinoid system and cancer: therapeutic implication. British journal of pharmacology. 2011; 163(7):1447-1463.

7. Bifulco M, Laezza C, Gazzerro $P$ and Pentimalli F. Endocannabinoids as emerging suppressors of angiogenesis and tumor invasion (review). Oncology reports. 2007; 17(4):813-816.

8. Cabral GA, Toney DM, Fischer-Stenger K, Harrison MP and Marciano-Cabral F. Anandamide inhibits macrophagemediated killing of tumor necrosis factor-sensitive cells. Life Sci. 1995; 56(23-24):2065-2072.

9. Klegeris A, Bissonnette CJ and McGeer PL. Reduction of human monocytic cell neurotoxicity and cytokine secretion by ligands of the cannabinoid-type CB2 receptor. Br J Pharmacol. 2003; 139(4):775-786.

10. Correa F, Hernangomez M, Mestre L, Loria F, Spagnolo A, Docagne F, Di Marzo V and Guaza C. Anandamide enhances IL-10 production in activated microglia by targeting $\mathrm{CB}(2)$ receptors: roles of ERK1/2, JNK, and NFkappaB. Glia. 2010; 58(2):135-147.

11. Eisenstein TK, Meissler JJ, Wilson Q, Gaughan JP and Adler MW. Anandamide and Delta9-tetrahydrocannabinol directly inhibit cells of the immune system via CB2 receptors. J Neuroimmunol. 2007; 189(1-2):17-22. 
12. Kishimoto S, Kobayashi Y, Oka S, Gokoh M, Waku K and Sugiura T. 2-Arachidonoylglycerol, an endogenous cannabinoid receptor ligand, induces accelerated production of chemokines in HL-60 cells. J Biochem. 2004; 135(4):517-524.

13. Joseph J, Niggemann B, Zaenker KS and Entschladen F. Anandamide is an endogenous inhibitor for the migration of tumor cells and $\mathrm{T}$ lymphocytes. Cancer Immunol Immunother. 2004; 53(8):723-728.

14. Ramer R and Hinz B. Inhibition of cancer cell invasion by cannabinoids via increased expression of tissue inhibitor of matrix metalloproteinases-1. J Natl Cancer Inst. 2008; 100(1):59-69.

15. Caffarel MM, Andradas C, Mira E, Perez-Gomez E, Cerutti C, Moreno-Bueno G, Flores JM, Garcia-Real I, Palacios J, Manes S, Guzman M and Sanchez C. Cannabinoids reduce ErbB2-driven breast cancer progression through Akt inhibition. Mol Cancer. 2010; 9:196.

16. Preet A, Qamri Z, Nasser MW, Prasad A, Shilo K, Zou X, Groopman JE and Ganju RK. Cannabinoid receptors, CB1 and CB2, as novel targets for inhibition of non-small cell lung cancer growth and metastasis. Cancer Prev Res (Phila). 2011; 4(1):65-75.

17. Diaz-Laviada I. The endocannabinoid system in prostate cancer. Nat Rev Urol. 2011; 8(10):553-561.

18. Endsley MP, Thill R, Choudhry I, Williams CL, KajdacsyBalla A, Campbell WB and Nithipatikom K. Expression and function of fatty acid amide hydrolase in prostate cancer. Int J Cancer. 2008; 123(6):1318-1326.

19. Bluher M, Engeli S, Kloting N, Berndt J, Fasshauer M, Batkai S, Pacher P, Schon MR, Jordan J and Stumvoll M. Dysregulation of the peripheral and adipose tissue endocannabinoid system in human abdominal obesity. Diabetes. 2006; 55(11):3053-3060.

20. Rodriguez LG, Wu X and Guan J-L. Wound-healing assay. Methods Mol Biol. 2005; 294:23-29.

21. Walter C, Ferreiros N, Bishay P, Geisslinger G, Tegeder I and Lötsch J. Exogenous delta-9-tetrahydrocannabinol influences circulating endogenous can-nabinoids in humans. In J Psychopharmacol. 2012; (accepted).

22. Kingsley PJ and Marnett LJ. Analysis of endocannabinoids by $\mathrm{Ag}+$ coordination tandem mass spectrometry. Analytical biochemistry. 2003; 314(1):8-15.

23. Glaser ST and Kaczocha M. Cyclooxygenase- 2 mediates anandamide metabolism in the mouse brain. The Journal of pharmacology and experimental therapeutics. 2010; 335(2):380-388.

24. Rouzer CA and Marnett LJ. Endocannabinoid oxygenation by cyclooxygenases, lipoxygenases, and cytochromes P450: cross-talk between the eicosanoid and endocannabinoid signaling pathways. Chem Rev. 2011; 111(10):5899-5921.

25. Di Marzo V, Melck $\mathrm{D}$, Orlando $\mathrm{P}$, Bisogno $\mathrm{T}$, Zagoory O, Bifulco M, Vogel Z and De Petrocellis L. Palmitoylethanolamide inhibits the expression of fatty acid amide hydrolase and enhances the anti-proliferative effect of anandamide in human breast cancer cells. The Biochemical journal. 2001; 358(Pt 1):249-255.

26. Ligresti A, Bisogno T, Matias I, De Petrocellis L, Cascio MG, Cosenza V, D‘Argenio G, Scaglione G, Bifulco M, Sorrentini I and Di Marzo V. Possible endocannabinoid control of colorectal cancer growth. Gastroenterology. $2003 ; 125(3): 677-687$.

27. Michalski CW, Oti FE, Erkan M, Sauliunaite D, Bergmann F, Pacher P, Batkai S, Muller MW, Giese NA, Friess H and Kleeff J. Cannabinoids in pancreatic cancer: correlation with survival and pain. International journal of cancer Journal international du cancer. 2008; 122(4):742-750.

28. Thors L, Bergh A, Persson E, Hammarsten P, Stattin P, Egevad L, Granfors T and Fowler CJ. Fatty acid amide hydrolase in prostate cancer: association with disease severity and outcome, CB1 receptor expression and regulation by IL-4. PloS one. 2010; 5(8):e12275.

29. Aggarwal BB, Shishodia S, Sandur SK, Pandey MK and Sethi G. Inflammation and cancer: how hot is the link? Biochemical pharmacology. 2006; 72(11):1605-1621.

30. Sheng H, Shao J, Kirkland SC, Isakson P, Coffey RJ, Morrow J, Beauchamp RD and DuBois RN. Inhibition of human colon cancer cell growth by selective inhibition of cyclooxygenase-2. The Journal of clinical investigation. 1997; 99(9):2254-2259.

31. Bishay P, Schmidt H, Marian C, Haussler A, Wijnvoord N, Ziebell S, Metzner J, Koch M, Myrczek T, Bechmann I, Kuner R, Costigan M, Dehghani F, Geisslinger G and Tegeder I. R-flurbiprofen reduces neuropathic pain in rodents by restoring endogenous cannabinoids. PloS one. 2010; 5(5):e10628.

32. Wechter WJ, Leipold DD, Murray ED, Jr., Quiggle D, McCracken JD, Barrios RS and Greenberg NM. E-7869 (R-flurbiprofen) inhibits progression of prostate cancer in the TRAMP mouse. Cancer Res. 2000; 60(8):2203-2208.

33. Hamtiaux L, Masquelier J, Muccioli GG, Bouzin C, Feron O, Gallez B and Lambert DM. The association of N-palmitoylethanolamine with the FAAH inhibitor URB597 impairs melanoma growth through a supraadditive action. BMC cancer. 2012; 12:92.

34. Endsley MP, Aggarwal N, Isbell MA, Wheelock CE, Hammock BD, Falck JR, Campbell WB and Nithipatikom $\mathrm{K}$. Diverse roles of 2-arachidonoylglycerol in invasion of prostate carcinoma cells: Location, hydrolysis and 12-lipoxygenase metabolism. International journal of cancer Journal international du cancer. 2007; 121(5):984-991.

35. Nomura DK, Morrison BE, Blankman JL, Long JZ, Kinsey SG, Marcondes MCG, Ward AM, Hahn YK, Lichtman AH, Conti B and Cravatt BF. Endocannabinoid hydrolysis generates brain prostaglandins that promote neuroinflammation. Science. 2011; 334(6057):809-813.

36. Fulton AM, Ma X and Kundu N. Targeting prostaglandin E EP receptors to inhibit metastasis. Cancer Res. 2006; 
66(20):9794-9797.

37. Kim R, Emi M and Tanabe K. Cancer immunoediting from immune surveillance to immune escape. Immunology. 2007; 121(1):1-14.

38. Blaukat A, Barac A, Cross MJ, Offermanns S and Dikic I. G protein-coupled receptor-mediated mitogen-activated protein kinase activation through cooperation of Galpha(q) and Galpha(i) signals. Mol Cell Biol. 2000; 20(18):68376848.

39. Tegeder I and Geisslinger G. Opioids as modulators of cell death and survival--unraveling mechanisms and revealing new indications. Pharmacol Rev. 2004; 56(3):351-369.

40. Grommes C, Karlo JC, Caprariello A, Blankenship DA, Dechant A and Landreth GE. The PPAR $\gamma$ agonist pioglitazone crosses the blood-brain barrier and reduces tumor growth in a human xenograft model. Cancer chemotherapy and pharmacology. 2013; 71(4):929-936.

41. Pang X, Wei Y, Zhang Y, Zhang M, Lu Y and Shen P. Peroxisome proliferator-activated receptor- $\gamma$ activation inhibits hepatocellular carcinoma cell invasion by upregulating plasminogen activator inhibitor-1. Cancer Sci. 2013; 104(6):672-680.

42. Hu G, Ren G and Shi Y. The putative cannabinoid receptor GPR55 promotes cancer cell proliferation. Oncogene. 2011; 30(2):139-141.

43. Nasser MW, Qamri Z, Deol YS, Smith D, Shilo K, Zou $\mathrm{X}$ and Ganju RK. Crosstalk between chemokine receptor CXCR4 and cannabinoid receptor CB2 in modulating breast cancer growth and invasion. PLoS One. 2011; 6(9):e23901.

44. Fanelli F, Di Lallo VD, Belluomo I, De Iasio R, Baccini M, Casadio E, Gasparini DI, Colavita M, Gambineri A, Grossi G, Vicennati V, Pasquali R and Pagotto U. Estimation of reference intervals of five endocannabinoids and endocannabinoid related compounds in human plasma by two dimensional-LC/MS/MS. J Lipid Res. 2012; 53(3):481493.

45. Banni S, Carta G, Murru E, Cordeddu L, Giordano E, Sirigu AR, Berge K, Vik H, Maki KC, Di Marzo V and Griinari M. Krill oil significantly decreases 2-arachidonoylglycerol plasma levels in obese subjects. Nutrition \& metabolism. 2011; 8(1):7. 